\title{
Domestic violence in a UK abortion clinic: anonymous cross-sectional prevalence survey
}

\author{
Silvia Motta, ${ }^{1}$ Loveday Penn-Kekana, ${ }^{2}$ Susan Bewley ${ }^{3}$
}

\begin{abstract}
${ }^{1}$ Midwife, Community Midwifery, Guy's and St Thomas' NHS Foundation Trust, London, UK ${ }^{2}$ Research Fellow, London School of Hygiene and Tropical Medicine, London, UK ${ }^{3}$ Professor of Complex Obstetrics, Women's Health Academic Centre, King's College London, London, UK
\end{abstract}

\section{Correspondence to} Ms Silvia Motta, St Thomas' Hospital, c/o Community Midwifery, 6th Floor North Wing, Westminster Bridge Road, London SE1 7EH, UK; silvia.motta@gstt.nhs.uk

Received 25 November 2013 Revised 26 March 2014 Accepted 22 April 2014 Published Online First 20 May 2014

\section{CrossMark}

\author{
To cite: Motta S, Penn- \\ Kekana L, Bewley S. J Fam \\ Plann Reprod Health Care \\ 2015;41:128-133.
}

\section{ABSTRACT}

Objective To measure the prevalence of domestic violence (DV) experienced by women seeking termination of pregnancy (TOP) in a UK abortion clinic.

Methods A cross-sectional anonymous questionnaire survey of all women aged over 16 years accessing a TOP clinic in inner London between 20 May 2012 and 2 July 2012. The main outcome measures were: distribution of questionnaires, response rate, lifetime prevalence of abuse, past-year prevalence of physical and sexual abuse, prevalence of physical abuse during current pregnancy, relationship of lifetime abuse to number of terminations, and receptivity to DV services.

Results Questionnaires were distributed to $46 \%$ (383/828) of women accessing the clinic. Response rate was 50\% (190/383). Lifetime prevalence of abuse was $16 \%$. Past-year prevalence of physical abuse was $11 \%$ and sexual abuse was $4 \%$. Prevalence of physical abuse during the current pregnancy was $4 \%$. Prevalence of lifetime abuse was lower in women having a first termination (12\%) versus one $(20 \%)$ or two or more previous terminations (24\%), although this was not statistically significant ( $p=0.192$ ). The majority $(75 \%)$ of participants expressing an opinion on the possibility of having a support service for DV in the abortion clinic setting were positive, unrelated to their personal experience, but some concerns were raised about implementation.

Conclusions In order to provide effective support for women, services require a needs assessment of their local population. Asking women presenting for abortion about DV, even anonymously, is challenging but feasible. Future work should be directed to women's unmet safety needs.

\section{INTRODUCTION}

Domestic violence (DV) is defined as "Any incident or pattern of incidents of

\section{Key message points}

- Domestic violence (DV) is associated with termination of pregnancy, especially repeat termination, with $4 \%$ of women reporting physical abuse during pregnancy in this study.

- Although the majority of women are amenable to the provision of DV support services, few disclosed personal experience of DV, yet one-third took away a concise support service information card.

- A simple anonymous prevalence estimate is feasible as part of a needs assessment of the local population when planning services.

controlling, coercive or threatening behaviour, violence or abuse between those aged 16 or over who are or have been intimate partners or family members regardless of gender or sexuality. This can encompass, but is not limited to, the following types of abuse: psychological, physical, sexual, financial and emotional". 1 Prevalence of DV varies according to the definition used, time period, severity and nature of the violence, as well as the setting. DV is a form of gender-based violence, which is highly prevalent worldwide, and an important public health issue, particularly for pregnant women. DV may start or escalate during pregnancy. ${ }^{2}$ Numerous studies show an association of DV with adverse maternal and infant outcomes. ${ }^{3-7}$

Attendance at health care facilities such as abortion or antenatal clinics brings women into contact with services and potential interventions. Professionals may be able to ask about DV and offer information and referral to support agencies. ${ }^{6}$ The prevalence of DV is high 
in pregnancy and may be a factor in women's decision making. Thus it might be prudent to ask women seeking abortion about DV, especially as unintended and unwanted pregnancy can be related to abuse and limited power of negotiation about sexual intercourse and contraception. ${ }^{59}$ A significant number of women requesting a termination of pregnancy (TOP) have been, or still are, in violent relationships. ${ }^{5} 910$ Estimates of DV in women seeking abortion vary between $7.8 \%$ in the current pregnancy to $12-22 \%$ in the preceding calendar year. ${ }^{3} 71112$ The only other two UK studies found that more than one in three abortion-seeking women had experienced lifetime DV and that women requesting a TOP were six times more likely to suffer physical abuse in the current relationship than those attending antenatal clinic for pregnancy care. ${ }^{5}{ }^{13}$ Women presenting for abortion have been reported to be receptive to screening in studies from Canada, Australia and the USA, ${ }^{6} 1415$ making this potentially a good time to offer an intervention.

In the UK, the Confidential Enquiry into Maternal and Child Health has highlighted the relationship between DV and maternal death ${ }^{16}$ and routine antenatal questioning is encouraged. ${ }^{17}$ There are no similar recommendations for TOP, although recently published National Institute for Health and Care Excellence guidelines recommend integrated commissioning of services, training of professionals, and the establishment of pathways to remove obstacles to disclosure and referral to specialist services. ${ }^{18}$

The aim of this study was to measure the prevalence of DV in a population of women seeking TOP in the UK.

\section{METHODS}

This cross-sectional descriptive survey formed part of a series of preparatory studies informing the feasibility and design of a health service intervention (Abortion in Context). The systematic review and stakeholder interviews are reported elsewhere. ${ }^{7}$

\section{Setting}

Four abortion clinics were approached [two private and two National Health Service (NHS)], of which one agreed to participate within the limited time frame to negotiate access. The survey was conducted in a large local clinic of a national not-for-profit abortion provider performing over 6500 terminations annually and covering approximately half of the NHS service provided by the independent sector for three inner-city London boroughs. The provider has a policy that requires that all women be asked "Are you safe at home?" during the woman's confidential consultation in order to facilitate disclosure of domestic abuse.

\section{Questionnaire survey}

The study tool was a modified version of the internationally validated Abuse Assessment Screen. ${ }^{19}$ [NB.
The authors are willing to supply a copy of the questionnaire on request.]

To minimise inconvenience, the survey consisted of just one A4 sheet with 11 questions: five demographic (age, ethnicity, number of children and previous abortions, relationship with partner); five abuse (asking about lifetime history of physical and emotional abuse, physical abuse in the past year and since the beginning of the pregnancy - asking specifically if there has been any hitting, kicking or slapping - and coercion in any sexual activity, and by whom the violence was perpetrated); and one about attitudes to support services ("Do you think having a support service for victims of abuse, domestic and sexual violence in abortion clinics could be a useful thing?") with a Yes/No answer. Respondents were also given space to write a free-text explanation for their answer to this question. The questionnaire was completed anonymously and in privacy. Confidentiality was respected at all times, as the personal data were not sufficient to track back to the woman's identity. This was clearly stated in the patient information sheet to reassure participants.

\section{Sample and distribution}

All consecutive women accessing the clinic for TOP between 20 May 2012 and 2 July 2012 were included. Exclusion criteria were age under 16 years, inability to speak or read English, or if the clinician felt it was unsafe to hand out the questionnaire. The distribution method was determined after discussion with the clinic manager and the nurse in charge in order to ensure privacy and avoid interference with clinical activities. Clinical staff (nurses and health care assistants) distributed the questionnaire to avoid coercion into participation. A leaflet accompanying the questionnaire explained the voluntary and anonymous nature of the study, briefly introduced the study and underlined the importance of investigating the issue. Contacts for national and local support services for women in abusive relationships were provided on the reverse of the leaflet. This information was also supplied in the form of a 'business card' stapled to the questionnaire itself so that it was easy for women to take the card and keep it somewhere safe. The nurses were instructed to only distribute the questionnaires when women were alone and to ask women to post completed questionnaires in sealed boxes strategically placed around the clinic. Consent to take part in the study was implied by completion of the questionnaire. Questionnaires were picked up weekly by the lead researcher. In addition to clinic policies, staff were briefed about the local hospital pregnancy DV service in case of disclosures.

\section{Statistical analysis}

Prevalence and comparisons of demographic characteristics and number of abortions were 
calculated using simple frequencies, $2 \times 2$ tables, Chi-square $\left(\chi^{2}\right)$ testing and $p$ values using a standard statistical package (SPSS V.19.0; IBM, Chicago, IL, USA). All comments were typed up and independently coded by two of the authors.

\section{RESULTS}

\section{Distribution and response rate}

During the study period 828 women accessed the clinic for TOP. Of 383 questionnaires given out (distribution rate 46\%), 190 were returned (response rate $50 \%)$. The stapled support service card had been removed from 66 questionnaires (uptake rate 35\%).

\section{Population}

The mean age of participants was 27 (range 16-44) years. There was a range of ethnicities: White British (35\%), Black (British, African or Caribbean) (30\%), Asian (8\%), White Other (13\%) and Other (14\%). Half the study population had no children (93, 49\%).

\section{Prevalence}

The prevalence of lifetime abuse was $16 \%$. The prevalence of physical abuse in the past year was $11 \%$ and sexual abuse in the past year was $4 \%$. The prevalence of DV in the current pregnancy was $4 \%$ (Table 1).

\section{Associations}

There were no significant associations between DV and age, ethnicity, number of children or stability of the relationship. There was a higher rate of both lifetime and past-year DV with increasing number of terminations, although this was not statistically significant $(p=0.196)$ (Table 1$)$.

Table 1 Prevalence of abuse: lifetime, past-year, during pregnancy, and in relation to the number of terminations of pregnancy

\begin{tabular}{lc}
\hline Prevalence of abuse & Frequency (\%) \\
\hline Type of abuse & $31 / 189(16)$ \\
Lifetime: abuse (all) & $20 / 188(11)$ \\
Last year: physical abuse & $8 / 188 \quad(4)$ \\
Last year: sexual abuse & $7 / 188 \quad(4)$ \\
Current pregnancy: physical abuse & $11 / 92(12)$ \\
Lifetime history of abuse in relation to number of abortions & $12 / 60(20)$ \\
No previous abortion & $8 / 33(24)$ \\
One previous abortion & $9 / 93(10)$ \\
Two or more previous abortions & $6 / 59(10)$ \\
Past-year history of physical abuse and number of abortions & \\
No previous abortion & $5 / 32(16)$ \\
One previous abortion & \\
Two or more previous abortions & \\
\hline$\chi^{2}=3.2$, df $=2, p=0.192$. The numbers do not always total 190 as \\
some data were missing.
\end{tabular}

Quantitative responses on usefulness of a DV support service The majority of respondents $(133 / 178,75 \%)$ supported the idea of a DV support service (Table 2), with no difference seen between those who had a previous history of DV $(26 / 35,74 \%)$ or not $(107 /$ 143, 75\%) (Table 3).

\section{Qualitative responses on usefulness of a DV support service}

There were 64 free-text comments; nine from women who had themselves experienced DV. The most common response was a comment giving support to the idea of a DV screening programme.

"I personally think it is a good idea as it would provide better care for women who are victims of abuse and violence."

"If someone is going through this the more help and support the better."

A number of respondents commented that the way that abortion services were organised made it ideal for a DV intervention; with confidentiality taken very seriously and it being a supportive and women-friendly setting. Similarly, they felt that this might be a time when women would wish to seek help.

"It seems like a safe private place to be able to talk about anything they might wish to disclose."

"I am no longer in this [violent] relationship but I feel if I was I would be more likely to seek help at this time due to my vulnerability."

Three women felt very differently, namely that a specialist DV setting was the best place to deal with DV and that it should not be addressed in abortion clinics.

"I feel other agencies would be more appropriate.

Please keep the focus on termination and aftercare.

This is not the place to talk about abuse."

Five of the women who commented reflected on their own experience of DV. Four were supportive of having such a service in termination care, and one commented that she was already receiving help and didn't need more.

"I already have a social worker, domestic health line [sic] and health visitor."

Table 2 Opinion on provision of support service for domestic violence within abortion clinics

\begin{tabular}{llc}
\hline Opinion & Frequency $(\boldsymbol{n})$ & Valid percentage (\%) \\
\hline Yes & 133 & 75 \\
No & 45 & 25 \\
Total responses & 178 & 100 \\
Missing - no response & 12 & \\
Total & 190 & \\
\hline
\end{tabular}


Table 3 Opinion on domestic violence (DV) support service within abortion clinic by women who did and did not have past experience of DV

\begin{tabular}{llrr}
\hline History & $\begin{array}{l}\text { Agreed with usefulness } \\
\text { of a DV support service }\end{array}$ & \multicolumn{2}{c}{$\boldsymbol{n}(\%)$} \\
\hline Positive history of DV & Yes & 26 & $(14)$ \\
& No & 9 & $(5)$ \\
Negative history of DV & Yes & 107 & $(56)$ \\
& No & 36 & $(19)$ \\
Not answered & & 12 & $(6)$ \\
Total & & $190(100)$ \\
\hline
\end{tabular}

DV, domestic violence.

\section{Disclosure}

During the study period no woman disclosed violence at the time of contact with the abortion clinic nor asked for help regarding a violent relationship.

\section{DISCUSSION}

\section{Key findings}

It is feasible to perform an anonymous prevalence study of DV in an abortion setting. A substantial minority of women had experienced lifetime and pastyear abuse, with $4 \%$ reporting current pregnancy physical abuse. There were higher, but not statistically significant, rates of DV in women with a greater number of terminations. Both the quantitative and qualitative results showed that the majority of women reported that a support service for DV in abortion clinics would be useful. As respondents only made up $23 \%$ of the clinic population, it is possible that the overall prevalence might have been higher or lower. Nevertheless, this prevalence is high, in terms of social and clinical significance, especially when considering other risks that concern termination and antenatal services.

\section{How do these results fit with the literature?}

The lifetime prevalence of abuse for this population was $16 \%$, lower than the rate of $25 \%$ found in a recent meta-analysis, ${ }^{7}$ and lower than the $35 \%$ lifetime prevalence of abuse in the only previous UK study of women seeking TOP. ${ }^{5}$ The prevalence of physical abuse in the past year found in this survey was $11 \%$, also slightly lower than those found in the literature review (12-22\%) but still clinically significant. Finally, the prevalence of physical abuse during the current pregnancy was found to be $4 \%$, which mirrors the literature review range of $4.0-7.8 \%{ }^{11}{ }^{20}$ It is higher than a previous UK study of $1.6 \%,{ }^{5}$ although this study only asked about the previous 1-2 week time-frame, and it is very similar to a recent UK study with a rate of $5.8 \% .^{13}$

Women having subsequent abortions are more likely to have suffered $\mathrm{DV}^{7}{ }^{21} 22$ which is consistent with this survey where prevalence of abuse was higher in women with a history of one or more previous abortions, although no statistically significant association was found, probably due to the small sample size.

The observation that the stapled card with information about local and national support services for DV was removed from $35 \%$ of the returned questionnaires was interesting, particularly as no woman disclosed violence or asked for help regarding a violent relationship during the study period. This suggests a mismatch between the policy of asking about women's safety and its implementation. It is impossible to say whether women, or their friends and families, might have been helped by this provision of information in view of the anonymity. Previous studies have examined disclosure in TOP clinics: questionnaires are highly acceptable, ${ }^{20}$ although nonresponding women differ from those who do respond and who had undergone a greater number of terminations. ${ }^{23}$ Women in violent relationships attend for follow-up ${ }^{12}$ and are more likely to know about DV community resources. ${ }^{11}$ It has previously been found that many women wish to talk about $\mathrm{DV}^{12}$ and cite their doctor as a source of information, ${ }^{11}$ although there are problems introducing universal screening in an abortion setting. ${ }^{6} 8$

The present study's findings can also be compared with those from different UK health care settings: a lifetime rate of abuse of $41 \%$ and past-year history of physical abuse of $17 \%$ in general practice clinics; ${ }^{24}$ a lifetime prevalence of abuse of $35 \%$ and past-year history of physical abuse of $6 \%$ in accident and emergency settings; $;^{25}$ and a lifetime history of abuse of $46 \%$ and a past-year prevalence of $17 \%$ in genitourinary medicine clinics. ${ }^{26}$ All three studies reported that women had a positive attitude towards being asked about DV, whereas the present study asked women about their attitudes to being offered a DV support service.

\section{Study strengths and limitations}

Strengths of the study were its anonymity, the ethical conduct and its simplicity. Limitations include the single setting and sample size. For the purpose of this 'real-life' study, the focus was a specific local population in South London. There may have been selection bias in the nurses' choice of participants to whom they handed questionnaires, or in the women's answers. Other researchers have achieved a very high (97\%) response rate, ${ }^{5}$ and it is possible that having a researcher on site would have resulted in a larger sample size. This is only the third study of prevalence in an abortion setting in the UK and the sixth in Europe; however, the study findings fit with the previous literature, thus improving reliability and generalisability.

\section{Implications for future research and clinical practice}

Abortion and DV are not easy fields to research, and this was reflected in the greater than anticipated difficulty in finding an abortion clinic that would host the study, and 
the need for negotiation with gatekeepers that was a complex process requiring external help and support. It is important that anyone considering replicating this study or performing a needs assessment considers the safety issues in detail. There is a tension between research interests and the safety of women and staff. Conflicts of interest have to be recognised.

Theoretically, early identification and effective intervention for violence may reduce repeat unintended pregnancy and TOP and as well as improve long-term health outcome. ${ }^{7}$ TOP settings provide an appropriate setting in which to assess screening and provide information about DV. Of all possible approaches, evaluated, intensive advocacy (that aims to provide women with information and support to facilitate access to community resources) appears the most promising in reducing physical abuse 1-2 years after intervention, but the impact on quality of life and mental health is not proven. ${ }^{7} 1827$ Consequently there is a need to consider new strategies, including alternative intervention models, and target perpetrators of DV in addition to the women affected. ${ }^{7} 28$

The present DV enquiry at the abortion clinic did not uncover the actual extent of abuse. Without trained practitioners and a specific service, routine enquiry may remain 'nominal', and be hard to implement. Although this study suggests that women would value the offer of help, 'screening' could do more harm than good and should not be introduced without rigorous testing. Nevertheless, staff need basic training in order to become more familiar with asking, and to be able to support women who do disclose violence and abuse, as part of good clinical practice and within policies and pathways of care. We would caution against adding to the clinical staff's workload, or creating barriers to women getting abortions. Clinicians or commissioners who wish to raise awareness or explore their own local prevalence could use our simple anonymous questionnaire, as long as they also provide relevant national and local support service information for women to take away safely.

\section{CONCLUSIONS}

Lifetime and current DV and abuse are prevalent in women seeking abortion. This is the first UK study to ask women's opinion about having DV support services within termination services. It provides evidence that women would welcome support and that a substantial proportion of patients (higher than those disclosing DV) take away support service information cards.

Acknowledgements The authors want to thank the women and staff who participated in this study, Mary Stewart who supervised Ms Motta's MSc, and Peter Milligan, statistician at King's College London, London, UK.

Funding The study was unfunded and undertaken as part of an MSc thesis.

Competing interests Professor Bewley has obtained charitable grant funding to study violence in pregnancy (Economic and
Social Research Council, Guys \& St Thomas' Charitable Foundation, Friends of Guys Charity) and received a fee for expert obstetric advisory work from Marie Stopes

International. Dr Penn-Kekana has received funding to perform a study on domestic violence and termination services (Friends of Guys Charity).

Ethics approval Ethical approval was obtained from London Westminster Adult Research Ethics Committee on 31 January 2012 (Ref. 12/LO/0165). Ethics and R\&D approval were obtained from the abortion provider on 9 May 2012 (Ref. 2012/05/SM).

\section{REFERENCES}

1 Home Office. Policy: Ending violence against women and girls in the UK. http://www.homeoffice.gov.uk/crime/ violence-against-women-girls/domestic-violence/ [accessed 10 January 2013].

2 Baccus L, Bewley S, Mezey G. Domestic violence in pregnancy. Foetal Matern Med Rev 2001;12:249-271.

3 Glander SS, Moore ML, Michielutte R, et al. The prevalence of domestic violence among women seeking abortion. Obstet Gynecol 1998;91:1002-1006.

4 Saftlas A, Wallis A, Shochet T, et al. Prevalence of intimate partner violence among an abortion clinic population. Am J Public Health 2010;100:1412-1415.

5 Keeling J, Birch L, Green P. Pregnancy counselling clinic: a questionnaire survey of intimate partner abuse. J Fam Plann Reprod Health Care 2004;30:165-168.

6 Weibe ER, Janssen P. Universal screening for domestic violence in abortion. Womens Health Issues 2001;11:436-441.

7 Hall M, Chappell L, Parnell B, et al. Association between domestic violence and termination of pregnancy: a systematic review and meta-analysis. PLOS Med 2014;11:e1001581.

8 Feder G, Davies RA, Baird K, et al. Identification and Referral to Improve Safety (IRIS) of women experiencing domestic violence with a primary care training and support programme: a cluster randomised controlled trial. Lancet 2011;378:1788-1795.

9 Romito P, Escriba-Aguir V, Pomicino L, et al. Violence in the life of women in Italy who have an elective abortion. Womens Health Issues 2009;19:335-343.

10 Russo N, Denious J. Violence in the lives of women having abortions: implications for practice and public policy. Prof Psychol Res Pr 2001;32:142-150.

11 Evins G, Chescheir N. Prevalence of domestic violence among women seeking abortion services. Womens Health Issues 1996;6:204-210.

12 Leung TW, Leung WC, Chan PL, et al. A comparison of the prevalence of domestic violence between patients seeking termination of pregnancy and other general gynecology patients. Int J Obstet Gynecol 2002;77:47-54.

13 Wokoma TT, Jampala M, Bexhell H, et al. A comparative study of the prevalence of domestic violence in women requesting a termination of pregnancy and those attending the antenatal clinic. BJOG 2014;121:627-633.

14 Webster J, Stratigos S, Grimes K. Women's responses to screening for domestic violence in a health-care setting. Midwifery 2001;17:289-294.

15 O'Reilly R, Beale B, Gillies D. Screening and intervention for domestic violence during pregnancy care: a systematic review. Trauma Violence Abuse 2010;11:190-201.

16 Lewis $\mathrm{G}$ (ed.). The Confidential Enquiry Into Maternal and Child Health (CEMACH). Saving Mothers' Lives: Reviewing Maternal Deaths to Make Motherhood Safer - 2003-2005. 
The Seventh Report on Confidential Enquiries into Maternal Deaths in the United Kingdom. London, UK: CEMACH, 2007.

17 Taskforce on the Health Aspects of Violence Against Women and Children. Report from the Domestic Violence Sub-group. Responding to Violence Against Women and Children - the Role of the NHS. 2010. http://fflm.ac.uk/upload/documents/ 1268670156.pdf [accessed 18 March 2014].

18 National Institute for Health and Care Excellence. Domestic Violence and Abuse: How Health Services, Social Care and the Organisations They Work With Can Respond Effectively. 2014. http://www.nice.org.uk/nicemedia/live/14384/66668/66668.pdf [accessed 18 March 2014].

19 McFarlane J, Parker B, Soeken K, et al. Assessing for abuse during pregnancy. Severity and frequency of injuries and associated entry into prenatal care. JAMA 1992;267: 3176-3178.

20 Whitehead A, Fanslow J. Prevalence of family violence among women attending an abortion clinic in New Zealand. Aust N Z J Obstet Gynecol 2005;45:321-324.

21 Rowland S. More than one abortion. J Fam Plann Reprod Health Care 2007;33:155-158.
22 Aston G, Bewley S. Abortion and domestic violence. Obstet Gynaecol 2009;11:163-168.

23 Roth L, Sheeder J, Teal S. Predictors of intimate partner violence in women seeking medical abortion. Contraception 2011;84:76-80.

24 Richardson J, Coid J, Petruckevitch A, et al. Identifying domestic violence. BMJ 2002;324:1-6.

25 Sethi D, Watts S, Zwi A, et al. Experience of domestic violence by women attending an inner city accident and emergency department. Emerg Med J 2004;21:180-184.

26 Loke WC, Bacchus L, Torres C, et al. Domestic violence in a genitourinary medicine setting - an anonymous prevalence study in women. Int J STD AIDS 2008;19:747-751.

27 Ramsay J, Carter Y, Davidson L, et al. Advocacy interventions to reduce or eliminate violence and promote the physical and psychological wellbeing of women who experience intimate partner abuse. Cochrane Database Syst Rev 2009;3: CD005043.

28 Hegarty K, O’Doerty L, Taft A, et al. Screening and counselling in the primary care setting for women who have experienced intimate partner violence (WEAVE): a cluster randomised controlled trial. Lancet 2013;382:249-258. 